\title{
Re-evaluation of pachycormid fishes from the Late Jurassic of Southwestern Germany
}

Erin E. Maxwell, Paul H. Lambers, Adriana López-Arbarello, and Günter Schweigert Acta Palaeontologica Polonica 65 (3), 2020: 429-453 doi:https://doi.org/10.4202/app.00749.2020

Pachycormidae is an extinct group of Mesozoic fishes that exhibits extensive body size and shape disparity. The Late Jurassic record of the group is dominated by fossils from the lithographic limestone of Bavaria, Germany that, although complete and articulated, are not well characterized anatomically. In addition, stratigraphic and geographical provenance are often only approximately known, making these taxa difficult to place in a global biogeographical context. In contrast, the late Kimmeridgian Nusplingen Plattenkalk of Baden-Württemberg is a well-constrained locality yielding hundreds of exceptionally preserved and prepared vertebrate fossils. Pachycormid fishes are rare, but these finds have the potential to broaden our understanding of anatomical variation within this group, as well as provide new information regarding the trophic complexity of the Nusplingen lagoonal ecosystem. Here, we review the fossil record of Pachycormidae from Nusplingen, including one fragmentary and two relatively complete skulls, a largely complete fish, and a fragment of a caudal fin. These finds can be referred to three taxa: Orthocormus sp., Hypsocormus posterodorsalis sp. nov., and Simocormus macrolepidotus gen. et sp. nov. The latter taxon was erected to replace "Hypsocormus" macrodon, here considered to be a nomen dubium. Hypsocormus posterodorsalis is known only from Nusplingen, and is characterized by teeth lacking apicobasal ridging at the bases, a dorsal fin positioned opposite the anterior edge of the anal fin, and a hypural plate consisting of a fused parhypural and hypurals. The holotype specimen contributes additional palaeobiological information, with small teleosteans preserved as gastric contents and ribs showing signs of callus formation. These new findings extend our knowledge of the anatomy and diversity of Pachycormidae, and represent an important first step in understanding factors controlling their distribution and morphological variation in the Late Jurassic of Europe.

Key words: Actinopterygii, Pachycormidae, Lagerstätte, Mesozoic, Kimmeridgian, Bavaria, Nusplingen.

Erin E. Maxwell [erin.maxwell@smns-bw.de] and Günter Schweigert [guenter.schweigert@smns-bw.de ], Staatliches Museum für Naturkunde Stuttgart, Rosenstein 1, 70191 Stuttgart, Germany. Paul H. Lambers [P.H.Lambers@uu.nl], Universiteitsmuseum Utrecht, Lange Nieuwstraat 106, 3512 PN

Utrecht, The Netherlands. Adriana López-Arbarello [a.lopez-arbarello@1rz.uni-muenchen.de], 
Department of Earth and Environmental Sciences, Pale ontology and Geobiology,

Ludwig-Maximilians-Universität München, Richard-Wagner-Str. 10, 80333 München, Germany.

This is an open-access article distributed under the terms of the Creative Commons

Attribution License (for details please see creativecommons.org), which permits unrestricted use, distribution, and reproduction in any medium, provided the original author and source are credited.

Foris Full text $(3,191.7 \mathrm{kB})$ 